\section{New products and} focus on impression materials and endodontics

\section{ENDO IRRIGATION WITH SONIC VIBRATION}

The Vibraject device, which effectively masks the pain and sensation of the local anaesthetic injection, can also be very useful in endodontic disinfection procedures. Perhaps the most important aspect of disinfection is the choice to use an active rather than passive irrigation method.

The Vibraject unit is simply attached to the irrigation syringe and uses sonic vibration (common in prophylaxis procedures) to dislodge material from the root canal.

Endodontic irrigation benefits from sonic vibration. Studies have shown that the root canal surface treated with $\mathrm{NaOCI}$ and a chelating agent such as EDTA, with sonic vibration, loosens the coherence of the smear layer and becomes thinner with more opened tubule orifices. Studies have found more smear layer removal and open tubules using sonic vibration with the solutions, than with the solutions alone.

Removal of the smear layer and the opening of the tubules provide a potentially tighter adaptation between

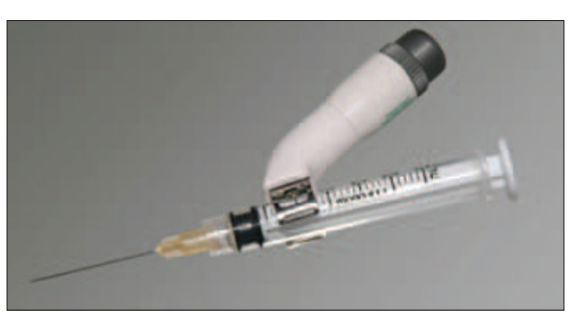

the obturation materials and the dentine walls of the preparation.

Sonic vibration needs a frequency of $100-200 \mathrm{~Hz}$. This is the equivalent of 6,000-12,000 revolutions per minute. Vibraject attaches to your current irrigation syringe and creates a needle frequency of $180 \mathrm{~Hz}$. There are no special accessories needed and no consumables.

Another advantage of sonic vibration is the removal of entrapped air and bubbles inside the root canal due to interactions between the irrigating solutions with the dentine cavity walls. Additionally, residual canal gases that may cause post-operative pain can also be reduced as well.

Reader response number 50

\title{
SIMPLER, SMARTER AND SHARPER INTRAORAL CAMERA
}

The Digital Doc Iris from Digital Dental is a simpler, smarter and sharper intraoral camera. It is simple to use because everything is integrated within the handpiece. It features a sure-touch multi-stop Focus Wheel, enabling precise focusing from macro to full smile with a touch of the finger, and a unique USB 2.0 connector that fits virtually all standard delivery unit couplings and plugs into your computer for fast image downloading and easy viewing. Its streamlined profile has a smaller, narrower soft-tip head which facilitates easier access to the retromolar region. It also features brilliant 8-point LED lighting and Sony's Hi-Resolution CCD for greater illumination and enhanced optical clarity. Reader response number 51
Please send product news information and images to Kate Maynard at the $B D J$,

Nature Publishing Group, The Macmillan Building, 4-6 Crinan Street, London N1 9XW. Product news is provided as a service to readers using text and images from the manufacturer, supplier or distributor and does not imply endorsement by the $B D J$. Normal and prudent research should be exercised before purchase or use of any product mentioned.

\section{IMPRESSION PROBLEMS SOLVED}

GC Europe has harnessed the best qualities of two great materials to form the next generation impression material: Vinyl PolyEther Silicone (VPES).

With EXA'lence GC takes dentistry to a new level by solving a number of common problems related to impression taking. With distinctively predictable impressions under all conditions, EXA'lence represents the next generation impression material.

EXA'lence possesses high elasticity and tear strength, combined with constant hydrophilicity and exceptional flow - the result being one of the most accurate impressions obtainable in the market today. EXA'lence is predictable in an unpredictable environment and virtually eliminates the need for retakes. EXA'lence provides an incredible level of detail that is paramount for optimal-fitting restorations. Every aspect of EXA'lence's unique chemistry is designed to make it the ideal material for every dentist and technicians on the path to clinical excellence.

EXA'lence offers: intrinsic hydrophilicity to capture the finest details, even in a moist environment; outstanding flow and thixotropic characteristics to capture all details and clear crisp margins; superior elasticity with a high degree of toughness to resist tearing; a pleasant mint taste; and a wide choice of setting times and viscosities. Reader response number 52 